https://doi.org/10.15407/dopovidi2021.03.072

УДК 546.(776+ 881.5)

К.В. Теребіленко ${ }^{1}$, https://orcid.org/0000-0003-2403-4347

В.О. Зозуля ${ }^{1}$, https://orcid.org/0000-0002-8930-681X

В.П. Чорній ${ }^{1,2}$, https://orcid.org/0000-0003-3727-5617

С.Г. Неділько ${ }^{1}$, https://orcid.org/0000-0003-2684-9806

М.С. Слободяник ${ }^{1}$, https://orcid.org/0000-0001-5196-6807

1 Київський національний університет ім. Тараса Шевченка

${ }^{2}$ Національний університет біоресурсів та природокористування України, Київ

E-mail: kterebilenko@gmail.com

\title{
Вплив концентрації ванадію(V) на будову скла $\mathrm{K}_{2} \mathrm{O}-\mathrm{P}_{2} \mathrm{O}_{5}-\mathrm{WO}_{3}-\mathrm{V}_{2} \mathrm{O}_{5}$
}

Представлено иленом-кореспондентом НАН України М.С. Слободяником

Встановлено, що характер структуроутворення скла для системи $\mathrm{K}_{2} \mathrm{O}_{-} \mathrm{P}_{2} \mathrm{O}_{5}-\mathrm{WO}_{3}-\mathrm{V}_{2} \mathrm{O}_{5}$ визначається співвідношенням $\mathrm{K} / \mathrm{V}$ і вмістом оксидів $\mathrm{WO}_{3}$ ma $\mathrm{V}_{2} \mathrm{O}_{5}$. Синтез скла реалізовано за двостадійною схемою, шо включає гомогенізачію при $1000{ }^{\circ} \mathrm{C}$ та відпал при $300{ }^{\circ} \mathrm{C}$. За даними IЧ-спектроскопї досліджених зразків встановлено наявність фосфатних, ванадатних та вольфраматних тетраедрів як каркасотвірних фрагментів. Також показано зростання вмісту $\mathrm{WO}_{6}^{6-}$ в отриманому склі з підвищенням конщентраціи WО ${ }_{3}$ у вихідній шихті. В межах концентраціі $V_{2} \mathrm{O}_{5}$ від 2,8 до 32,5 \% утворюються прозорі рентгенаморфні стекла від жовтого до світло-коричневого кольору.

Ключові слова: фосфатне скло, вольфрамат, ванадат, будова скла, розплав.

Неорганічні люмінофори на основі фосфатного скла знайшли широке використання в покриттях світлодіодних ламп, люмінесцентних візуалізувальних пристроях та інших оптичних системах [1, 2]. Особливий інтерес фундаментальної та прикладної науки зосереджено на легованих оксидних та фторидних стеклах. Завдяки унікальній можливості керовано змінювати концентрацію активатора, температуру плавлення та густину модифікованого фосфатного скла вдається адаптувати властивості матеріалу під технологічні умови експлуатації [3]. Перевагою саме фосфатних стекол є той факт, що розчинність оксидів рідкісноземельних елементів у фосфатних системах на три порядки вища, ніж у боратних, германатних, ванадатних і молібдатних розплавах [2].

Серед відомих фосфатних люмінесцентних стекол для $39 \mathrm{ZnO}-35 \mathrm{P}_{2} \mathrm{O}_{5}-20 \mathrm{CaO}-5 \mathrm{TiO}_{2}-$ $1 \mathrm{Eu}_{2} \mathrm{O}_{3}[2]$ показано їх високу термічну стабільність і високий квантовий вихід люмінесцен-

Ци т у в ан н я: Теребіленко К.В., Зозуля В.О., Чорній В.П., Неділько С.Г., Слободяник М.С. Вплив концентрації ванадію(V) на будову скла $\mathrm{K}_{2} \mathrm{O}-\mathrm{P}_{2} \mathrm{O}_{5}-\mathrm{WO}_{3}-\mathrm{V}_{2} \mathrm{O}_{5}$. Допов. Нащ. акад. наук Укр. 2021. № 3. C. 72-77. https://doi.org/10.15407/dopovidi2021.03.072 
Вплив конщентращії ванадію( $\mathrm{V})$ на будову скла $\mathrm{K}_{2} \mathrm{O}-\mathrm{P}_{2} \mathrm{O}_{5}-\mathrm{WO}_{3}-\mathrm{V}_{2} \mathrm{O}_{5}$

ції при вмісті оксиду європію від 1 до 7 \% мол. У разі вищого вмісту активатора спостерігається поява кристалічної фази, що супроводжується пониженням інтенсивності люмінесценції в червоній області спектра [2]. Для систем 45PbO-45P $\mathrm{O}_{5}-9,5 \mathrm{Ga}_{2} \mathrm{O}_{3}-0,5 \mathrm{Ln}_{2} \mathrm{O}_{3}$ ( $\mathrm{Ln}=\mathrm{Eu}, \mathrm{Dy}, \mathrm{Tb}$ або Er) [4] також показано високу стабільність і перспективні оптичні властивості. За результатами детальних досліджень фосфатних стекол встановлено необхідність використання додаткових модифікаторів у складі фосфатного скла, такого як $\mathrm{Na}_{2} \mathrm{O}-\mathrm{P}_{2} \mathrm{O}_{5}$, $\mathrm{CaO}-\mathrm{P}_{2} \mathrm{O}_{5}$ та $\mathrm{BaO}-\mathrm{P}_{2} \mathrm{O}_{5}$, які мають значний потенціал зі спектроскопічної точки зору як чудові матриці для легування [2, 4]. Проблема високої гігроскопічності вирішується додаванням $\mathrm{ZnO}, \mathrm{V}_{2} \mathrm{O}_{5}$ [1], $\mathrm{MoO}_{3}$ [5] та $\mathrm{WO}_{3}$ [6]. Наведені модифікатори належать до умовних склотвірних компонентів, які значним чином впливають на будову одержаного скла. Так, встановлено, що використання оксиду вольфраму у фосфатних стеклах підвищує їх прозорість і стабільність у вологому повітрі. Однак природа структурних фрагментів, що є каркасотвірними у такому склі, зазнає змін за рахунок збільшення координаційного числа вольфраму від 4 у $\mathrm{WO}_{4}^{2-}$ до 6 у випадку конденсованих $\mathrm{WO}_{6}^{6-}$ [7]. 3 хімічної точки зору для реалізації оптимального складу фосфато-вольфраматного скла важливим завданням є встановлення ключових факторів впливу на форми і тип аніонів, що присутні у таких комбінованих сольових розплавах та утворених ними стеклах. Оскільки вольфраматні та молібдатні групи також можуть виступати сенсибілізаторами люмінесценції, встановлення областей існування аніонних форм та їх взаємоперетворення є важливими для визначення оптимальних параметрів для люмінесцентних склоподібних матеріалів.

Експериментальна частина. Як вихідні реагенти використовували: $\mathrm{K}_{2} \mathrm{WO}_{4}$ (х.ч.), $\mathrm{KPO}_{3}$ (х.ч.) та $\mathrm{V}_{2} \mathrm{O}_{5}$ (ч.д.а.) без попереднього очищення. Розраховані кількості компонентів поміщали у платинові тиглі об'ємом 20 мл і витримували в муфельній печі шахтного типу при $1000{ }^{\circ} \mathrm{C}$ протягом 2 год. При цьому досягалася повна гомогенність у одержаному розплаві. За умов охолодження до $500{ }^{\circ} \mathrm{C}$ зі швидкістю $100^{\circ}$ /год явища кристалізації не спостерігалося. Далі скло виливали на графітову підкладку та гартували в муфельній печі при $300{ }^{\circ} \mathrm{C}$ протягом 2 год. Надалі піч вимикали і скло в ній повільно охолоджувалося до кімнатної температури. Отримане прозоре скло характеризується кольором від світло-жовтого до коричневого залежно від вмісту ванадію.

Дифрактограми записували за допомогою автоматичного порошкового дифрактометpa Shimadzu XRD 6000 у режимі відбиття від плоских зразків (CuK $K_{\alpha}$-випромінювання 3 $\lambda=1,54178 \AA$; метод $2 \theta$ безперервного сканування зі швидкістю 1,2 хв; діапазон кутів $2 \theta$ від 5,0 до 70,0; графітовий монохроматор перед детектором). ІЧ-спектри записано на приладі "Perkin Elmer Spectrum BX" у таблетках KBr для діапазону частот від 400 до $4000 \mathrm{~cm}^{-1}$. Електронні спектри записані на приладі “Thermo Scientific Evolution 600”, у діапазоні 190600 нм з роздільною здатністю 0,2 нм. Сканувальна електронна мікроскопія проводилася на приладі JEOL JSM 6060 LV з напиленням золота.

Результати та іх обговорення. Для більшості представників неорганічного скла характерно використання такого склотвірного компонента, як $\mathrm{P}_{2} \mathrm{O}_{5}$ [1]. Перевагами його використання є широкі концентраційні межі включення інших оксидів, у тому числі каркасотвірних $\left(\mathrm{ZnO}, \mathrm{TiO}_{2}, \mathrm{CaO}\right)$, і порівняно невисокі температури синтезу та розм'якшення. Однак для систем, що містять катіони лужних та лужноземельних металів у співвідношеннях M/P <1 ( $\mathrm{M}$ - Li, Na, K; Ca, Sr, Ba), що відповідає ультрафосфатному розрізу, знижується 

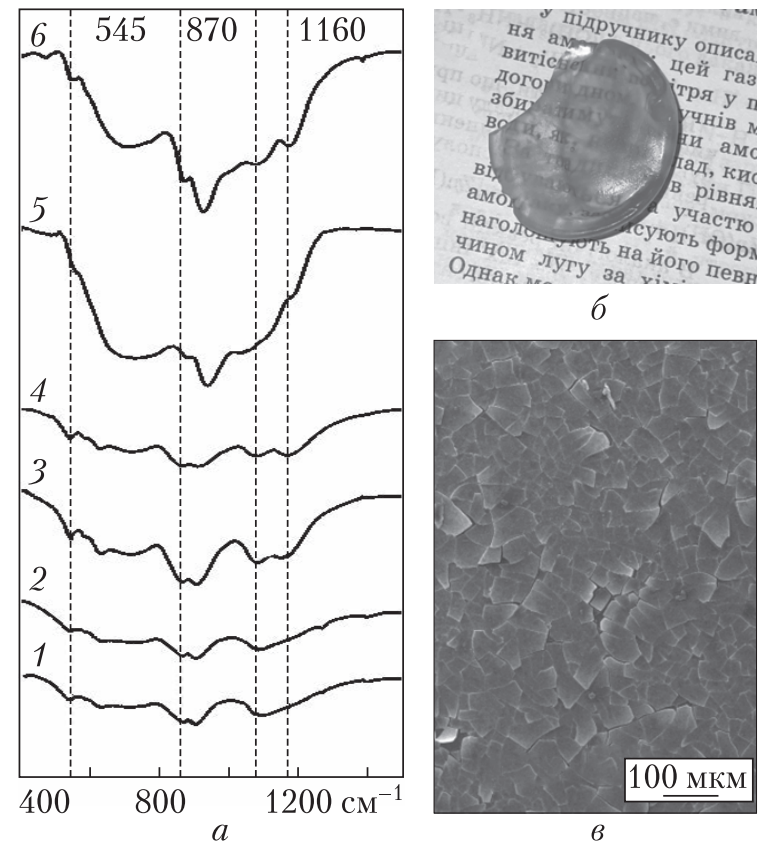

Puc. 1. ІЧ-спектри стекол ( $a$ : 1-6- номер зразка (див. табл. 1)), фотографія скла № 1 (б) і СЕМзображення його поверхні (в) стійкість відповідного скла у вологому повітрі. Такий недолік звужує коло можливого застосування поліфункціональних стекол на основі фосфатів. Одним із шляхів покращення та оптимізації властивостей фосфатних стекол є введення умовно склотвірних агентів, таких як $\mathrm{MoO}_{3}, \mathrm{WO}_{3}, \mathrm{Bi}_{2} \mathrm{O}_{3}, \mathrm{~V}_{2} \mathrm{O}_{5}$ [5]. Однак у зв'язку зі схильністю таких систем до самочинного відновлення $\mathrm{W}^{+6}-\mathrm{W}^{+5}$ i $\mathrm{Mo}^{+6}-\mathrm{Mo}^{+5}$ спостерігається значне зниження прозорості отриманого аморфного матеріалу та поява забарвлення від світло-синього до чорного [8]. Однією $з$ передумов такого відновлення є співвідношення M/P <1 ( $\mathrm{M}-\mathrm{Li}, \mathrm{Na}, \mathrm{K})$, тому для успішного синтезу прозорого скла ми вибрали систему, що містить комбінацію оксидів $\mathrm{K}_{2} \mathrm{O}, \mathrm{P}_{2} \mathrm{O}_{5}$ та $\mathrm{WO}_{3}$ у співвідношенні $\mathrm{K} / \mathrm{P}=3,0$ та $\mathrm{K} / \mathrm{W}=3,0$, при цьому для модифікації оптичних властивостей одержаного скла введено домішку $\mathrm{V}_{2} \mathrm{O}_{5}$ у кількості від 2,8 до 33,4 \% мол. (табл. 1, рис. 1, $a$ ).

Важливо зазначити, що для одержання прозорих стекол принциповим є гартування скла при $300{ }^{\circ} \mathrm{C}$ для зняття внутрішньої напруги. У випадку скла $\mathrm{K}_{2} \mathrm{O}-\mathrm{P}_{2} \mathrm{O}_{5}-\mathrm{WO}_{3}-\mathrm{V}_{2} \mathrm{O}_{5}$ за умов гартування утворюється прозоре жовтувате скло (див. рис. 1, б), поверхня якого характеризується наявністю дрібних (до 10 мкм) лусочок (див. рис. 1, в), утворення яких, імовірно, пов'язане з перепадом температур під час гартування. Важливо відзначити, що гартування при вищій температурі призводить до розтріскування готового скла.

Відомо, що ванадієвмісні стекла можуть характеризуватися забарвленням від світложовтого до коричневого, при цьому ванадій у складі люмінесцентних стекол може виступати сенсибілізатором люмінесценції домішкових іонів, таких як $\mathrm{Eu}^{3+}$. Для оптимізації властивостей люмінесцентних стекол складу $\mathrm{K}_{2} \mathrm{O}-\mathrm{P}_{2} \mathrm{O}_{5}-\mathrm{WO}_{3}-\mathrm{V}_{2} \mathrm{O}_{5}$ важливо встановити, як змінюється будова і властивості скла зі зміною концентрації оксиду ванадію(V) та

Таблиия 1. Склад скла

та співвідношення K/V у ньому

\begin{tabular}{|l|c|c|c|c|c|}
\hline $\begin{array}{l}\text { Номер } \\
\text { зразка }\end{array}$ & $\mathrm{K}_{2} \mathrm{O}$ & $\mathrm{P}_{2} \mathrm{O}_{5}$ & $\mathrm{WO}_{3}$ & $\mathrm{~V}_{2} \mathrm{O}_{5}$ & $\mathrm{~K} / \mathrm{V}$ \\
\hline 1 & 48,5 & 16,2 & 32,5 & 2,8 & 17 \\
2 & 47,8 & 15,9 & 31,9 & 4,4 & 11 \\
3 & 47,0 & 15,7 & 31,3 & 6,0 & 8 \\
4 & 46,1 & 15,4 & 30,8 & 7,7 & 6 \\
5 & 40,9 & 13,6 & 27,3 & 18,2 & 2 \\
6 & 33,5 & 11,0 & 22,1 & 33,4 & 1 \\
\hline
\end{tabular}

визначити область існування аморфного скла для наведеного складу. Отримані результати стануть основою для легування активаторами на основі рідкісноземельних катіонів і дизайну нових неорганічних люмінофорів.

Для вмісту $\mathrm{K}_{2} \mathrm{O} 33,5-48,5$ \% мол. склад підбирався таким чином, що вміст $\mathrm{V}_{2} \mathrm{O}_{5}$ змінювався від 2,8 до 33,4 \% мол., а співвідношення K/P та K/W залишалося рівним 3,0.

Усі утворені стекла є прозорими, стійкими на повітрі до вологи та забарвлені від світлоISSN 1025-6415. Dopov. Nac. akad. nauk Ukr. 2021. № 3 
жовтого $\left(2,8 \% \mathrm{~V}_{2} \mathrm{O}_{5}\right)$ до коричневого (33,4\% $\mathrm{V}_{2} \mathrm{O}_{5}$ ) кольору. Аморфність стекол була підтверджена рентгенофазовим аналізом перетертого скла. Типовий вигляд рентгенограми зразка 48,5 $\mathrm{K}_{2} \mathrm{O}-16,2 \mathrm{P}_{2} \mathrm{O}_{5}-32,5 \mathrm{WO}_{3}-2,8 \mathrm{~V}_{2} \mathrm{O}_{5}$ в межах кутів $2 \theta=5-70^{\circ}$ наведено на рис. 2 . Характерне для рентгенаморфних фосфатних стекол гало спостерігається в області кутів $2 \theta=25-35^{\circ}$, як це було раніше відмічено для систем $\mathrm{PbO}-\mathrm{P}_{2} \mathrm{O}_{5}-\mathrm{Ga}_{2} \mathrm{O}_{3}-\mathrm{Ln}_{2} \mathrm{O}_{3}$ [9] та $\mathrm{ZnO}-\mathrm{P}_{2} \mathrm{O}_{5}-\mathrm{BaO}-\mathrm{TiO}_{2}-\mathrm{Eu}_{2} \mathrm{O}_{3}$ [2]. На відміну від систем, що досліджені в роботах [2, 8, 9], кристалічних включень для скла $\mathrm{K}_{2} \mathrm{O}-$ $\mathrm{P}_{2} \mathrm{O}_{5}-\mathrm{WO}_{3}-\mathrm{V}_{2} \mathrm{O}_{5}$ не виявлено.

Одним із найважливіших інструментів для встановлення особливостей будови багато-

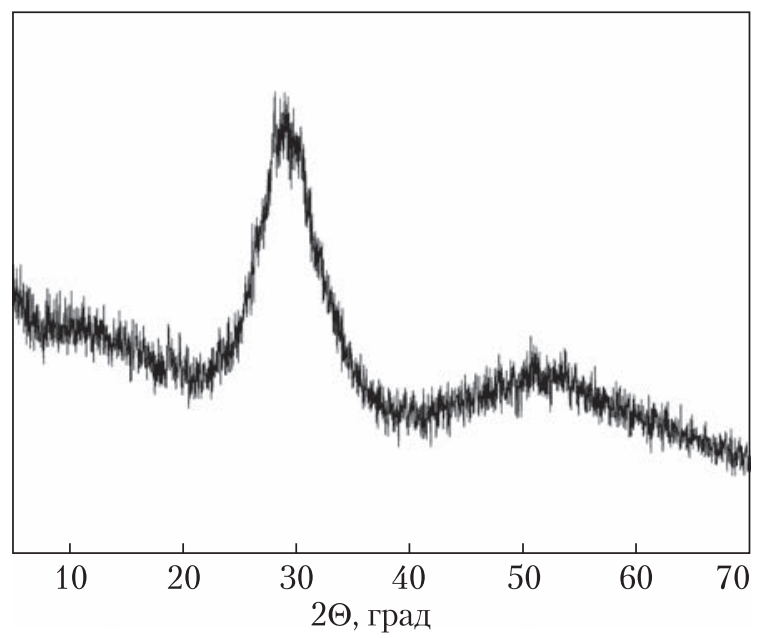

Puc. 2. Рентгенограма скла $48,5 \mathrm{~K}_{2} \mathrm{O}-16,2 \mathrm{P}_{2} \mathrm{O}_{5}-$ $32,5 \mathrm{WO}_{3}-2,8 \mathrm{~V}_{2} \mathrm{O}_{5}$ компонентних стекол є ІЧ-спектроскопія, особливо в області 200-1500 $\mathrm{cm}^{-1}$. Так, для розгляду будови скла на основі фосфатів основним каркасотвірним агентом вважаються тетраедри $\mathrm{PO}_{4}{ }^{3-}$, які завдяки ковалентному зв'язку $\mathrm{P}-\mathrm{O}-\mathrm{P}$ формують ланцюги та цикли в межах каркаса скла. Важливо відзначити, що у порівнянні з іншими фрагментами у склі, такими як $\mathrm{K}-\mathrm{O}-\mathrm{P}$, саме внесок фосфатних груп є визначальним у фізико-хімічних властивостях аморфної фази. В ІЧ-спектрах (див. рис. 1, $a$ ) досліджених зразків валентні коливання $\mathrm{PO}_{4}^{3-}$ спостерігаються в межах $1050-1100 \mathrm{~cm}^{-1}$, а коливання $\mathrm{P}-\mathrm{O}-\mathrm{P}-$ в околі $718 \mathrm{~cm}^{-1}$ (табл. 2), що вказує на домінування ортофосфатних груп. Оксид $\mathrm{WO}_{3}$ належить до умовно склотвірних, тому виявляє свою функцію у випадку присутності фосфату як основного компонента скла, при цьому йому відповідають два типи структурних фрагментів $\mathrm{WO}_{4}{ }^{2-}$ та $\mathrm{WO}_{6}{ }^{6-} . \mathrm{У}$ випадку тетраедричного оточення спостерігаються деформаційні коливання при 420 та $440 \mathrm{~cm}^{-1}$, які присутні на усіх досліджених спектрах. На противагу цьому для $\mathrm{WO}_{6}^{6-}$ груп інтенсивні смуги спостерігаються при 850-885 $\mathrm{cm}^{-1}$. Зі зростанням вмісту $\mathrm{V}_{2} \mathrm{O}_{5}$ від 2,8 до 32,5 \% збільшується інтенсивність смуги при $870 \mathrm{~cm}^{-1}$, що відповідає валентним коливанням $\mathrm{VO}_{4}{ }^{3-}$ та $\mathrm{WO}_{4}{ }^{2-}$. Крім цього, збільшується інтенсивність широкої смуги $715-725 \mathrm{~cm}^{-1}$, що відповідає деформаційним коливанням ванадатного та вольфраматного тетраедрів.

Таблиця 2. Характеристичні смуги в ІЧ-спектрах для стекол

\begin{tabular}{|c|c|c|c|c|}
\hline $\begin{array}{c}\text { Номер } \\
\text { зразка }\end{array}$ & $v\left(\mathrm{PO}_{4}^{3-}, \mathrm{VO}_{4}^{3-}\right)$ & $v\left(\mathrm{WO}_{6}^{6-}\right)$ & $\begin{array}{c}\delta(\mathrm{P}-\mathrm{O}-\mathrm{P}), \\
\delta(\mathrm{P}-\mathrm{O}-\mathrm{W})\end{array}$ & $\delta\left(\mathrm{PO}_{4}^{3-}, \mathrm{VO}_{4}{ }^{3-}\right)$ \\
\hline 1 & 1097 & 905,868 & - & 631,541 \\
2 & 1089 & 905,868 & 732 & 639,545 \\
3 & 1145,1083 & 904,866 & 722 & 637,544 \\
4 & 1164,1078 & 909,864 & 718 & 628,542 \\
5 & 1178,1048 & 936,880 & 731 & 554 \\
6 & 1171,1072 & 927,872 & 722 & 550,472 \\
\hline
\end{tabular}


Зі зменшенням концентрації оксиду вольфраму форма існування вольфраму(VI) у складі скла зазнає значних змін і відповідає збільшенню вмісту $\mathrm{WO}_{6}^{6-}$. Так, інтенсивність смуги при 855-875 см$^{-1}$, що відповідає саме збільшенню вмісту оксиду вольфраму(VI) у склі, зростає пропорційно введеному $\mathrm{WO}_{3}$. На противагу цьому смуга при $1086 \mathrm{~cm}^{-1}$ істотних змін не зазнає. Отже, можна стверджувати, що у розплавах системи $\mathrm{K}_{2} \mathrm{O}-\mathrm{P}_{2} \mathrm{O}_{5}-$ $\mathrm{WO}_{3}-\mathrm{V}_{2} \mathrm{O}_{5}$ наявні структурні фрагменти: ортофосфату, ортованадату, $\mathrm{WO}_{4}^{2-}$ та $\mathrm{WO}_{6}^{6-} \cdot 3 \mathrm{i}$ зростанням вмісту ванадатної компоненти збільшується інтенсивність смуги, що відповідає валентному коливанню $\mathrm{VO}_{4}^{3-}$, а характер розщеплення смуг в околі $1000-1100 \mathrm{~cm}^{-1}$ вказує на домінування ортофосфату та ортованадату у складі скла $\mathrm{K}_{2} \mathrm{O}-\mathrm{P}_{2} \mathrm{O}_{5}-\mathrm{WO}_{3}-\mathrm{V}_{2} \mathrm{O}_{5}$. Важливо врахувати, що з підвищенням вмісту оксиду вольфраму(VI) у складі шихти від 22,1 до 32,5 \% мол. зростає частка $\mathrm{WO}_{6}^{6-}$, а зі збільшенням частки оксиду ванадію(V) зростає вміст саме ортованадатних груп.

Таким чином, виявлені закономірності можуть бути використані для синтезу люмінесцентних стекол шляхом введення до їх складу іонів рідкісноземельних елементів.

\section{ЦИТОВАНА ЛІТЕРАТУРА}

1. Shaaban K.S., Yousef E.S., Mahmoud S.A., Wahab E.A., Shaaban E.R. Mechanical, structural and crystallization properties in titanate doped phosphate glasses. J. Inorg. Organomet. Polymer. Mater. 2020. 30. P. 4655-4663. https://doi.org/10.1007/s10904-020-01574-x

2. Jha K., Jayasimhadri M. Structural and emission properties of $\mathrm{Eu}^{3+}$-doped alkaline earth zinc-phosphate glasses for white LED applications. J. Am. Ceram. Soc. 2017. 100, Iss. 4. P. 1402-1411. https://doi.org/10.1111/ jace.14668

3. Brow R.K. Review: the structure of simple phosphate glasses. J. Non-Cryst. Solids. 2000. 263-264. P. 1-28. https://doi.org/10.1016/S0022-3093(99)00620-1

4. Pisarski W.A., Żur L., Goryczka T., Sołtys M., Pisarska J. Structure and spectroscopy of rare earth - Doped lead phosphate glasses. J. Alloys Compd. 2014. 587. P. 90-98. https://doi.org/10.1016/j.jallcom.2013.10.106

5. Abbas L., Bih L., Nadiri A., El Amraoui Y., Khemakhem H., Mezzane D. Chemical durability of $\mathrm{MoO}_{3}-\mathrm{P}_{2} \mathrm{O}_{5}$ and $\mathrm{K}_{2} \mathrm{O}-\mathrm{MoO}_{3}-\mathrm{P}_{2} \mathrm{O}_{5}$ glasses. J. Therm. Anal. Calorim. 2007. 90, № 2. P. 453-458. https://doi.org/10.1007/ s10973-006-7673-4

6. Kalenda P., Koudelka L., Mošner P., Montagne L., Revel B. Glass-forming ability and the structure of glasses in the $\mathrm{BaO}-\mathrm{WO}_{3}-\mathrm{P}_{2} \mathrm{O}_{5}$ system. J. Non-Cryst. Solids. 2020. 541. 120145. https://doi.org/10.1016/j.jnoncrysol. 2020.120145

7. Ihyadn A., Lahmar A., Mezzane D., Bih L., Alimoussa A., Amjoud M., El Marssi M., Luk’yanchuk I.A. Structural, elelectrical and energy storage properties of $\mathrm{BaO}-\mathrm{Na}_{2} \mathrm{O}-\mathrm{Nb}_{2} \mathrm{O}_{5}-\mathrm{WO}_{3}-\mathrm{P}_{2} \mathrm{O}_{5}$ glass - ceramics system. Mater. Res. Express. 2019. 6, № 11. 115203. https://doi.org/10.1088/2053-1591/ab4569

8. Oliva I., Masuno A., Inoue H., Sakamoto M., Morita K. Adiabatic small polaron hopping in $\mathrm{K}_{2} \mathrm{O}-\mathrm{WO}_{3}-$ $\mathrm{Nb}_{2} \mathrm{O}_{5}-\mathrm{P}_{2} \mathrm{O}_{5}$ glasses. Solid State Ionics. 2014. 255. P. 56-59. https://doi.org/10.1016/j.ssi.2013.12.002

9. Maity A., Jana S., Ghosh S., Sharma S. Spectroscopic investigation on europium $\left(\mathrm{Eu}^{3+}\right)$ doped strontium zinc lead phosphate glasses with varied $\mathrm{ZnO}$ and $\mathrm{PbO}$ compositions.J. Non-Cryst. Solids. 2020.550. 120322. https:// doi.org/10.1016/j.jnoncrysol.2020.120322

Надійшло до редакції 05.03.2021

\section{REFERENCES}

1. Shaaban, K. S., Yousef, E. S., Mahmoud, S. A., Wahab, E. A. \& Shaaban, E. R. (2020). Mechanical, structural and crystallization properties in titanate doped phosphate glasses. J. Inorg. Organomet. Polymer. Mater., 30, pp. 4655-4663. https://doi.org/10.1007/s10904-020-01574-x 
2. Jha, K. \& Jayasimhadri, M. (2017). Structural and emission properties of $\mathrm{Eu}^{3+}$-doped alkaline earth zincphosphate glasses for white LED applications. J. Am. Ceram. Soc., 100, Iss. 4, pp. 1402-1411. https://doi. org/10.1111/jace.14668

3. Brow, R. K. (2000). The structure of simple phosphate glasses. J. Non-Cryst. Solids, 263-264, pp. 1-28. https:// doi.org/10.1016/S0022-3093(99)00620-1

4. Pisarski, W. A., Żur, L., Goryczka, T., Sołtys, M. \& Pisarska, J. (2014). Structure and spectroscopy of rare earth - Doped lead phosphate glasses. J. Alloys Compd., 587, pp. 90-98. https://doi.org/10.1016/j.jallcom. 2013.10.106

5. Abbas, L., Bih, L., Nadiri, A., El Amraoui, Y., Khemakhem, H., \& Mezzane, D. (2007). Chemical durability of $\mathrm{MoO}_{3}-\mathrm{P}_{2} \mathrm{O}_{5}$ and $\mathrm{K}_{2} \mathrm{O}-\mathrm{MoO}_{3}-\mathrm{P}_{2} \mathrm{O}_{5}$ glasses. J. Therm. Anal. Calorim., 90, № 2, pp. 453-458. https://doi. org/10.1007/s10973-006-7673-4

6. Kalenda, P., Koudelka, L., Mošner, P., Montagne, L. \& Revel, B. (2020). Glass-forming ability and the structure of glasses in the $\mathrm{BaO}-\mathrm{WO}_{3}-\mathrm{P}_{2} \mathrm{O}_{5}$ system. J. Non-Cryst. Solids, 541, 120145. https://doi.org/10.1016/j. jnoncrysol.2020.120145

7. Ihyadn, A., Lahmar, A., Mezzane, D., Bih, L., Alimoussa, A., Amjoud, M., El Marssi, M. \& Luk'yanchuk, I. A. (2019). Structural, elelectrical and energy storage properties of $\mathrm{BaO}-\mathrm{Na}_{2} \mathrm{O}-\mathrm{Nb}_{2} \mathrm{O}_{5}-\mathrm{WO}_{3}-\mathrm{P}_{2} \mathrm{O}_{5}$ glassceramics system. Mater. Res. Express, 6, № 11, 115203. https://doi.org/10.1088/2053-1591/ab4569

8. Oliva, I., Masuno, A., Inoue, H., Sakamoto, M. \& Morita, K. (2014). Adiabatic small polaron hopping in $\mathrm{K}_{2} \mathrm{O}-$ $\mathrm{WO}_{3}-\mathrm{Nb}_{2} \mathrm{O}_{5}-\mathrm{P}_{2} \mathrm{O}_{5}$ glasses. Solid State Ionics, 255, pp. 56-59. https://doi.org/10.1016/j.ssi.2013.12.002

9. Maity, A., Jana, S., Ghosh, S. \& Sharma, S. (2020). Spectroscopic investigation on europium (Eu ${ }^{3+}$ ) doped strontium zinc lead phosphate glasses with varied $\mathrm{ZnO}$ and $\mathrm{PbO}$ compositions. J. Non-Cryst. Solids, 550, 120322. https://doi.org/10.1016/j.jnoncrysol.2020.120322

Received 05.03.2021

K.V. Terebilenko ${ }^{1}$, https://orcid.org/0000-0003-2403-4347

V.O. Zozulya ${ }^{1}$, https://orcid.org/0000-0002-8930-681X

V.P. Chornii ${ }^{1,2}$, https://orcid.org/0000-0003-3727-5617

S.G. Nedilko ${ }^{1}$, https://orcid.org/0000-0003-2684-9806

M.S. Slobodyanik ${ }^{1}$, https://orcid.org/0000-0001-5196-6807

${ }^{1}$ Taras Shevchenko National University of Kyiv

${ }^{2}$ National University of Life and Environmental Sciences of Ukraine, Kyiv

E-mail: kterebilenko@gmail.com

INFLUENCE OF THE VANADIUM(V) CONCENTRATION

ON THE STRUCTURE OF $\mathrm{K}_{2} \mathrm{O}-\mathrm{P}_{2} \mathrm{O}_{5}-\mathrm{WO}_{3}-\mathrm{V}_{2} \mathrm{O}_{5}$ GLASSES

The peculiarities of a glass formation for the $\mathrm{K}_{2} \mathrm{O}-\mathrm{P}_{2} \mathrm{O}_{5}-\mathrm{WO}_{3}-\mathrm{V}_{2} \mathrm{O}_{5}$ system is determined by the $\mathrm{K} / \mathrm{V}$ ratio and the content of $\mathrm{WO}_{3}$ and $\mathrm{V}_{2} \mathrm{O}_{5}$ oxides. The synthesis of glass has been carried out in a two-stage scheme, including the homogenization at $1000^{\circ} \mathrm{C}$ and the annealing at $300{ }^{\circ} \mathrm{C}$. According to the IR spectroscopy of the studied samples, the presence of phosphate, vanadate, and tungstate tetrahedra as network-forming fragments has been established. An increase in the content of $\mathrm{WO}_{6}^{6-}$ in the obtained glass with the concentration of $\mathrm{WO}_{3}$ in the initial charge is shown. In the interval of $\mathrm{V}_{2} \mathrm{O}_{5}$ concentration from 2.8 to $32.5 \%$, transparent amorphous glasses with a color from yellow to light brown are obtained.

Keywords: phosphate glass, tungstate, vanadate, structure of a glass, melt. 